\title{
VCAM1-targeted RNA interference inhibits the proliferation of human oral squamous carcinoma HN12 cells
}

\author{
LEGANG SUN ${ }^{1}$, LING LIU ${ }^{2}$, TINGTING YU ${ }^{1}$, QIUQIN WANG ${ }^{3}$ and HONGHAI FU ${ }^{1}$ \\ ${ }^{1}$ Department of Oral Surgery; ${ }^{2}$ Room of Gastroscopy; ${ }^{3}$ Department of Rehabilitation, \\ The Affiliated Hospital of Binzhou Medical College, Binzhou, Shandong 256603, P.R. China
}

Received December 9, 2015; Accepted November 21, 2017

DOI: $10.3892 / \mathrm{ol} .2018 .8034$

\begin{abstract}
In the present study, RNA interference (RNAi) was used to investigate the effect of vascular cell adhesion molecule 1 (VCAMI) silencing on the proliferation of human oral squamous carcinoma HN12 cells. HN12 cells were divided into three groups: The untreated blank control cell group $(\mathrm{CK})$, the negative control group transfected with non-homologous vector (NC) and the positive group transfected with the target sequence $V C A M 1$ small hairpin RNA (KD). Reverse-transcription polymerase chain reaction and western blot analysis were used to examine the effects of $V C A M 1$-knockdown on the mRNA expression of $V C A M 1$ and subsequent protein expression. Furthermore, the HN12 cell growth inhibition rate was detected using the cell counting kit-8 method. The VCAM1-targeted lentiviral vector RNAi significantly inhibited VCAM1 mRNA, and subsequent protein, expression. Compared with the NC group, the VCAM1 gene knockdown efficiency was $\sim 85 \%$, while the expression level of VCAM1 protein was reduced by $\sim 74 \%$ in KD group cells. In addition, cell growth was significantly inhibited in the KD group, with a growth inhibition rate of $\sim 34 \%$. Therefore, this targeted lentiviral vector RNAi effectively inhibited $V C A M 1$ gene, and subsequent protein, expression, as well as the proliferation of oral squamous carcinoma cells. These results may provide an experimental reference for the diagnosis and treatment of oral squamous cell carcinoma.
\end{abstract}

Correspondence to: Dr Legang Sun, Department of Oral Surgery, The Affiliated Hospital of Binzhou Medical College, 661 Yellow River Road, Binzhou, Shandong 256603, P.R. China

E-mail: legangsun@sina.com

Abbreviations: VACM1, vascular cell adhesion molecule 1; RISC, RNA-induced silencing complex; NC, negative control; MOI, multiplicity of infection; GFP, green fluorescence protein; SD, standard deviation

Key words: vascular cell adhesion molecule 1, RNA interference, oral squamous carcinoma cell, HN12, proliferation, genetic

\section{Introduction}

Oral squamous cell carcinoma, characterized by its poor overall prognosis, complex pathogenesis and high mortality rate, is the sixth most common type of malignant cancer globally (1). Approximately 300,000 oral squamous cell carcinoma cases are reported annually (1), with the likelihood of severe progression partnered with a high risk of nodal metastasis and locoregional invasion (2). In addition, the combined actions of various factors, including genetic factors and tumor microenvironment are implicated in the complex pathogenesis of oral squamous cell carcinoma $(3,4)$. Despite recent advances in surgery, chemotherapy and radiotherapy, the 5-year survival rate of oral squamous cell carcinoma has remained at $\sim 50 \%$ for the past 10 years (5). Therefore, to potentially identify targets that may aid therapeutic intervention, further research is required to investigate the underlying mechanisms implicated during progression of oral squamous cell carcinoma.

Vascular cell adhesion molecule 1 (VCAM1) is a member of the immunoglobulin superfamily that binds integrin receptors $\alpha 4 \beta 1$ and $\alpha 4 \beta 7$ (6). The VCAM1 gene is $\sim 25 \mathrm{~kb}$ long and is located in the lp31-32 human chromosomal region (6). The VCAM1 protein may potentially be released from the cell membrane and function in a soluble form in response to environmental cues $(7,8)$. As an immunoglobulin-like adhesion molecule, VCAM1 serves a significant role in various pathophysiological tissues $(9,10)$. Aberrant expression of VCAM1 frequently occurs in various types of cancer (10). For example, abnormal expression of VCAM1 is associated with the metastasis of gastric carcinoma $(11,12)$. Furthermore, VCAM1 is implicated in the preferential attachment of highly metastatic melanoma cells to microvesicles within the tumor microenvironment (13). VCAM1 is also key metastasis of breast cancer to the lung and, thus, may present a potential therapeutic target (10). Functioning as an environmental sensor that regulates adult neurogenesis, VCAM1 expression is induced in the neural stem cell niche of the subventricular zone (14). Therefore, a potentially useful approach for assessing prognosis in patients with oral tongue squamous cell carcinoma may be monitoring changes in VCAM1 expression in lymphatic vessels (15).

RNA interference (RNAi) refers to the gene-silencing phenomenon induced by small molecules of double-stranded RNA (dsRNA) (16), in which RNA molecules inhibit gene 
expression or translation, by neutralizing targeted mRNA molecules $(17,18)$. RNAi is controlled by the RNA-induced silencing complex (RISC), and initiated in the cell cytoplasm by short double-stranded RNA molecules that interact with the catalytic RISC component Argonaute (16). The synthetic dsRNA, which is then introduced into cells, has the ability to induce the suppression of target genes (16). Recently, RNAi has become a key technology for identifying the components within particular cell processes.

VCAM1 expression has been demonstrated to be induced in oral tongue squamous cell carcinoma (15). In addition, a previous study demonstrated that overexpression of the VCAMI gene serves a potential role in oral squamous cell carcinoma development, which was closely associated with lymph node metastasis and angiogenesis (19). However, there remain few studies on the effect of VCAMI silencing on the proliferation of human oral squamous carcinoma (15). Therefore, to provide an experimental basis for the diagnosis and colorectal cancer treatment, the present study aimed to investigate the effect of $V C A M 1$ silencing on the proliferation of human oral squamous carcinoma HN12 cells.

\section{Materials and methods}

Construction of VCAM1 silencing HN12 cell lines. HN12 human oral squamous carcinoma cells (Michigan State University, East Lansing, MI, USA) were cultured in Dulbecco's Modified Eagle's Medium (DMEM) supplemented with 10\% fetal bovine serum (Gibco; Thermo Fisher Scientific, Inc., Waltham, MA, USA), and incubated at $37^{\circ} \mathrm{C}$ with $5 \% \mathrm{CO}_{2}$. To create the VCAMI short hairpin RNA (shRNA)-silenced sub-cell lines, the following shRNA sequence was designed against the VCAM1 gene: 5'-GGCTGGAGATAGACTTAC TTTCAAGAGAAGTAAGTCTATCTCCAGCCTTTTTTA CGCGT-3'. The VCAM1 RNAi was purchased from the Daan Gene Co., Ltd. (Guangzhou, China), and the HN12 cells were transfected with the plasmids, psPAX2 and pMD2.G using Lipofectamine ${ }^{\circledR} 2000$ transfection reagent according to the manufacturer's protocol (Invitrogen; Thermo Fisher Scientific, Inc.). After $48 \mathrm{~h}$ of transfection, HN12 Cells were divided into three groups: The untreated blank control cell group (CK), the negative control group transfected with non-homologous vector (NC) and the positive group transfected with the VCAMl-kncodown shRNA sequence (KD).

Infection efficiency measurement. For cell infection, the HN12 cells $\left(2.5 \times 10^{5}\right.$ cells/well $)$ were seeded in 24 -well plates and cultured in an incubator for $12 \mathrm{~h}$. Following this, 1, 1.0, 5.0 or $10.0 \mu \mathrm{l}$ of blank lentiviruses with green fluorescence protein (GFP) $\left[1 \times 10^{9}\right.$ transducing units (TU)/ml] were added to the wells. For each concentration of lentiviruses, three wells were used. After $12 \mathrm{~h}$, lentiviruses were washed with PBS and the cells were further cultured in DMEM containing $10 \%$ fetal bovine serum in an incubator at $37^{\circ} \mathrm{C}$ with $5 \% \mathrm{CO}_{2}$. The infection efficiency was observed after $48 \mathrm{~h}$, and the multiplicity of infection (MOI) was evaluated using a fluorescence microscope to analyze the expression level of GFP.

Reverse transcription-quantitative polymerase chain reaction $(R T-q P C R)$. In 6 -well plates, $3 \times 10^{5} \mathrm{HN} 12$ cells were cultured for 3 days at $37^{\circ} \mathrm{C}$ with $5 \% \mathrm{CO}_{2}$, and cell culture was continued for an additional 2 days at $37^{\circ} \mathrm{C}$ with $5 \% \mathrm{CO}_{2}$ when the MOI was $>50 \%$. Following digestion and centrifugation $(400 \mathrm{x} \mathrm{g})$ for $5 \mathrm{~min}$ at $37^{\circ} \mathrm{C}$, total RNA was extracted using TRIzol ${ }^{\circledR}$ reagent (Thermo Fisher Scientific, Inc., Waltham, MA, USA) according to the manufacturer's protocol. RNA was reverse-transcribed using the FastQuant RT kit (Tiangen Biotech Co., Ltd., Beijing, China) at $37^{\circ} \mathrm{C}$. Next, SYBR Green I-labeled PCR product (Takara Bio, Inc., Otsu, Japan) was used according to the manufacturer's protocol for fluorescent qPCR to obtain quantification cycle $(\mathrm{Cq})$ values. The following thermocycling conditions were maintained: $95^{\circ} \mathrm{C}$ for $3 \mathrm{~min} ; 95^{\circ} \mathrm{C}$ for $10 \mathrm{sec}$ and $60^{\circ} \mathrm{C}$ for $30 \mathrm{sec}$ for 39 cycles; and melting curve analysis using increase from 65.0 to $95.0^{\circ} \mathrm{C}$ in $0.5^{\circ} \mathrm{C}$ increments for $5 \mathrm{sec}$. Finally, the $2^{-\Delta \Delta \mathrm{Cq}}$ method (20) was used to analyze differences in relative gene expression in each sample, using $\beta$-actin as the internal reference gene. Primer sequences are listed in Table I.

Western blot analysis. The HN12 cells were collected 7 days the lentivirus infection and lysed in SDS sample buffer [100 mM Tris- $\mathrm{HCl}$ ( $\mathrm{pH}$ 6.8), $10 \mathrm{mM}$ ethylenediaminetetraacetic acid, $4 \%$ SDS, and $10 \%$ glycine]. Next, the protein content was evaluated using the Lowry method (21). To detect target proteins, equal amounts of protein samples were separated by SDS-PAGE (12\% gel) and transferred to polyvinylidene difluoride membranes. Next, the membranes were incubated with TBST [25 mM Tris (pH 7.4) $150 \mathrm{mM} \mathrm{NaCl,} \mathrm{0.1 \%} \mathrm{Tween-20]}$ containing 5\% non-fat dry milk at room temperature for $1 \mathrm{~h}$. Following washing with TBST for 3 times, the membranes were probed with the primary antibody anti-VCAM1 rabbit mAb (dilution, 1:500; cat. no. ab106777; Abcam, Cambridge, UK) and anti- $\beta$-actin rabbit $\mathrm{mAb}$ (dilution, 1:500; cat. no. ab6272; Abcam) at $4{ }^{\circ} \mathrm{C}$ overnight, followed by incubation with a goat anti-rabbit IgG horseradish peroxidase-linked antibody (dilution, 1:1,500; cat. no. 7074 CST Biological Reagents Co., Ltd., Shanghai, China) for $1 \mathrm{~h}$ at room temperature. Finally, the blots were detected with an enhanced chemiluminescence detection kit (Pierce; Thermo Fisher Scientific, Inc.) following the manufacturer's protocol. $\beta$-actin was used as the reference control. The relative expression level of VCAM1 was acquired based on the gray values, and analyzed with Quantity One 1-D analysis software v4.6 (Bio-Rad Laboratories, Inc., Hercules, CA, USA).

Cell Counting Kit-8 (CCK-8) assay. The lentivirus transfected HN12 cells were seeded into 96 -well plates at a density of $2 \times 10^{3}$ cells per well and incubated for $12 \mathrm{~h}$ at $37^{\circ} \mathrm{C}$. Then cells were treated with $20 \mathrm{ml}$ Lipofectamine ${ }^{\circledR}$-small interfering RNA (siRNA) complexes, which contained $2 \mathrm{nM}$ siRNA. Cells treated with scrambled siRNA were used as negative controls. Cell proliferation rate was measured 5 days following transfection, by adding $10 \mathrm{ml} \mathrm{CCK}-8$ solution (Takara Bio, Inc.) to each well, followed by incubation at $37^{\circ} \mathrm{C}$ for $2 \mathrm{~h}$. Absorbance was evaluated at $450 \mathrm{~nm}$ by spectrophotometry using a SpectraMax 190 Microplate Reader (Molecular Devices, LLC, Sunnyvale, CA, USA). In each assay, six parallel wells were included, and the results were collected to evaluate the mean of three independent experiments. 
Table I. Primers for $A C T B$ and $V C A M 1$.

\begin{tabular}{llll}
\hline Gene & Accession number & \multicolumn{1}{c}{ Primer sequences $\left(5^{\prime}-3^{\prime}\right)$} & Product size, bp \\
\hline ACTB & NM_001101.3 & F: TGTTACAGGAAGTCCCTTGCCATC & 85 \\
& NM_001078.3 & R: CTGTGTGGACTTGGGAGAGGAC & \\
& F: TTCTGTGCCCACAGTAAGG & 95 \\
& R: GCAGCTTTGTGGATGGATTC &
\end{tabular}

${ }^{a}$ Accession numbers from the National Center for Biotechnology Information. VCAM1, vascular cell adhesion molecule $1 ; A C T B, \beta$-actin; F, forward; R, reverse.
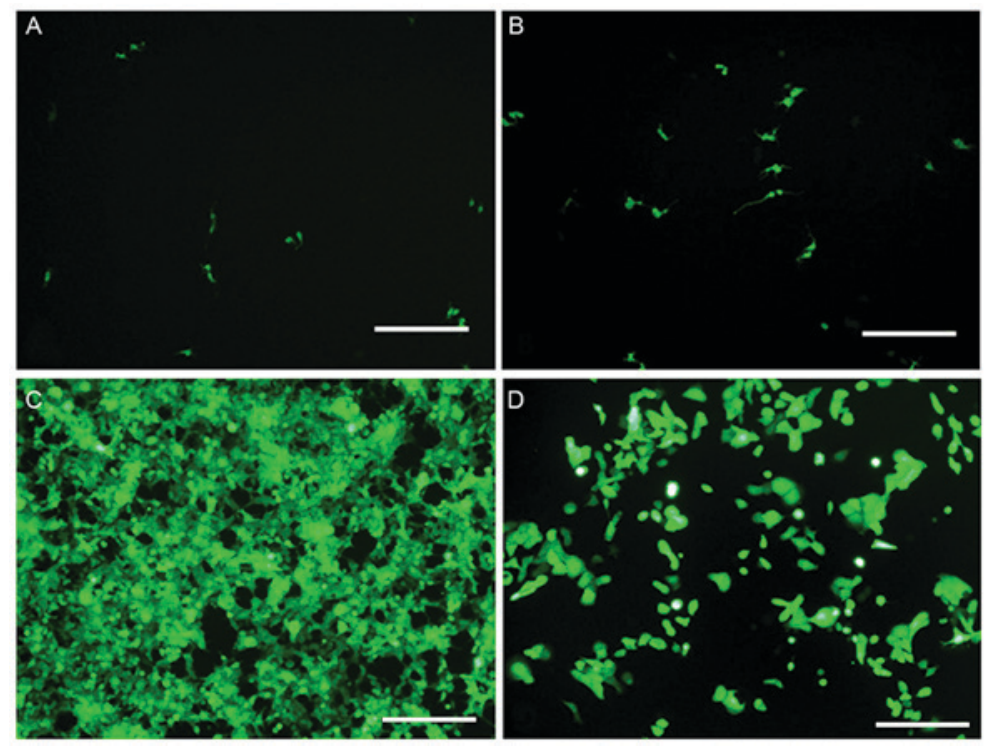

Figure 1. The expression of green fluorescent protein in HN12 cells transfected with lentiviral vectors, viewed with fluorescence microscopy. (A) MOI=1, (B) $\mathrm{MOI}=10$, (C) MOI=50, (D), MOI=100. Scale bar, $100 \mu \mathrm{m}$. MOI, multiplicity of infection.

Statistical analysis. SPSS 17.0 statistical software (SPSS, Inc., Chicago,IL,USA) was used fordataanalysis.Datawere expressed as the mean \pm standard deviation. One-way analysis of variance was performed to analyze the effect of $V C A M 1$ silencing on the proliferation of $\mathrm{HN} 12$ cells. $\mathrm{P}<0.05$ was considered to indicate a statistically significant difference.

\section{Results}

Transfection efficiency of lentivirus. Fluorescence microscopy was used to detect the expression level of GFP. Following this, the transfection efficiency of viruses was evaluated by analyzing the MOI of HN12 cells. It was observed that the infection rate was $<10 \%$ when the MOI was 1.0 (Fig. 1A). Furthermore, the infection rate was $10-20 \%$ at an MOI of 10.0 (Fig. 1B). At a MOI of 50, the toxic side effects of the virus were negligible and cell density was not significantly altered (Fig. 1C). At this MOI, the transfection efficiency was $\sim 95 \%$ (Fig. 1C). However, a cytotoxic effect was observed with a MOI of 100 , and the infection rate was $>95 \%$ (Fig. 1D). Therefore, an optimum MOI of 50 was selected for use in the present study. Compared with the NC group, the knockdown efficiency of the VCAM1 gene was $85 \%$, and the expression level of VCAM1 protein was reduced by $\sim 74 \%$ in the KD group.
VCAM1 gene expression in HN12 cells. As the lentiviral vector system was efficiently transduced into HN12 cells, the level of VCAM1 gene expression was further analyzed. RT-qPCR results indicated that there was no statistical difference in VCAM1 gene expression in HN12 cells between the NC group and the $\mathrm{CK}$ group ( $\mathrm{P}>0.05 ;$ Fig. 2). However, compared with the $\mathrm{NC}$ group, VCAM1 gene expression was significantly reduced in the KD group $(\mathrm{P}<0.05)$, and the knockdown efficiency of VCAM1 was $~ 85 \%$ (Fig. 2).

VCAM1 protein expression in HN12 cells. Western blot analysis was applied to detect the expression level of VCAM1 protein in the HN12 cells infected by lentiviral RNAi vectors. No significant difference in VCAM1 protein expression level was observed between the $\mathrm{CK}$ group and the $\mathrm{NC}$ group (P>0.05) (Fig. 3). Compared with the NC group, the expression level of VCAM1 was significantly decreased, by $\sim 74 \%$, in the KD cell group $(\mathrm{P}<0.05$; Fig. 3$)$.

Cell growth inhibition rate as evaluated by a CCK-8 assay. To investigate the effect of VCAM1 silencing on cell proliferation, the HN12 cell growth inhibition rate was assayed using the CCK-8 method. Compared with the NC group, cell growth was significantly inhibited in the KD group $(\mathrm{P}<0.05)$, with a 


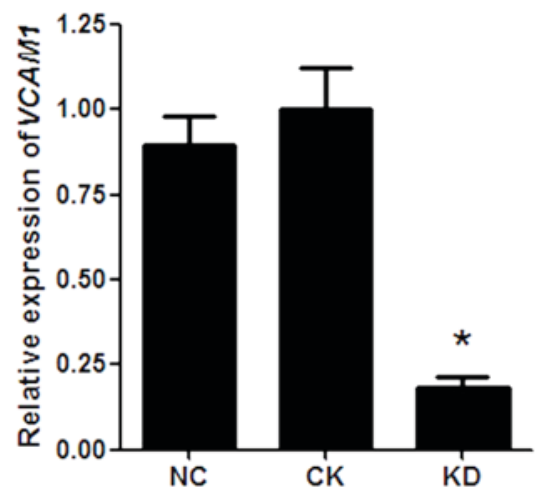

Figure 2. VCAM1 mRNA expression in HN12 cells transduced by a lentiviral RNA interference vector. $\beta$-actin was used as the reference gene. Values are expressed as the mean \pm standard deviation $(n=3)$. mRNA expression in the NC group was set at $1 .{ }^{*} \mathrm{P}<0.05$, compared with $\mathrm{NC}$ group. VCAM1, vascular cell adhesion molecule 1; NC, negative control; $\mathrm{CK}$, blank control; $\mathrm{KD}$, knockdown.

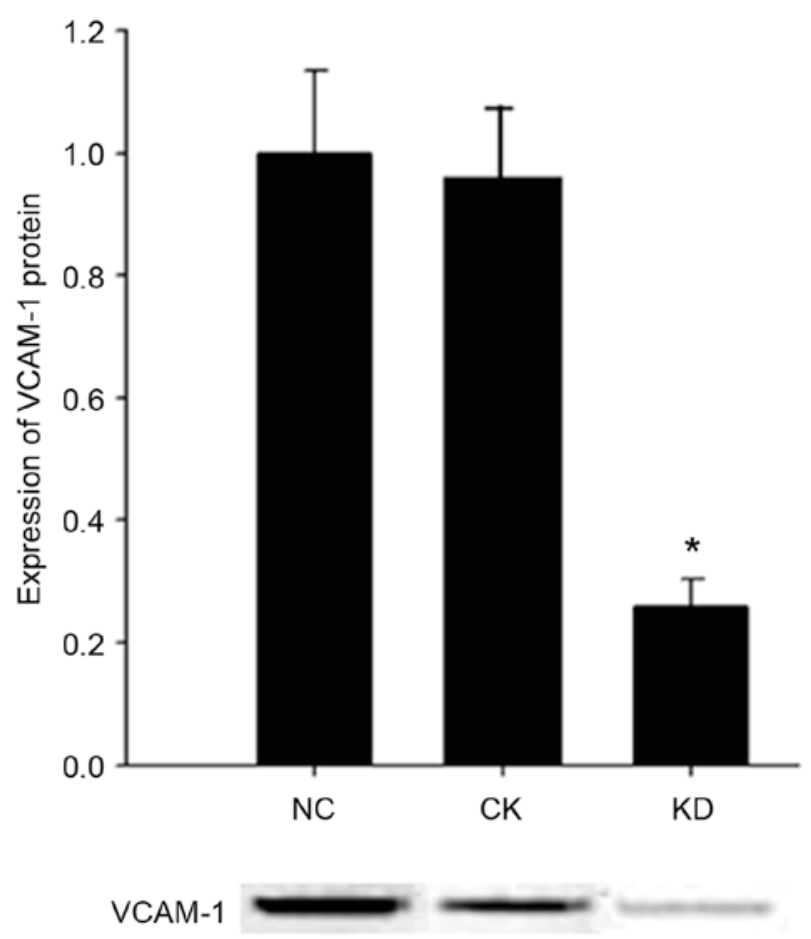

$\beta$-actin

Figure 3. Expression of VCAM1 protein in HN12 cells transduced by a lentiviral RNA interference vector. Values are expressed as the mean \pm standard deviation $(\mathrm{n}=3)$. ${ }^{*} \mathrm{P}<0.05$, compared with NC group. VCAM1, vascular cell adhesion molecule 1; NC, negative control; CK, blank control; $\mathrm{KD}$, knockdown.

growth inhibition rate of $\sim 33.97 \%$ (Fig. 4). However, no significant inhibitory effect on cell growth was observed in the CK group ( $\mathrm{P}>0.05$; Fig. 4).

\section{Discussion}

In the present study, RNAi was used to investigate the effect of $V C A M 1$ silencing on the proliferation of human oral squamous

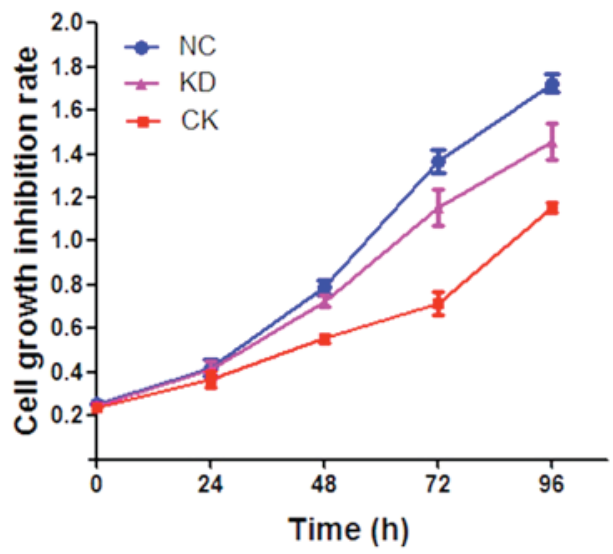

Figure 4. Cell multiplication in HN12 cells evaluated using a Cell Counting kit-8 assay. NC, negative control; CK, blank control; KD, knockdown.

carcinoma HN12 cells. The results of RT-qPCR and western blotting demonstrated that RNAi using a VCAM1-targeted lentiviral vector significantly inhibited the expression of VCAM1. In addition, cell growth was significantly inhibited in the KD group cells, with a cell growth inhibition rate of $\sim 33.97 \%$. A previous study indicated that VCAM1 serves a significant role as a molecular switch in the various signal transduction pathways of tumor cells (6). VCAM1 not only induces the recruitment of tumor angiogenesis factors, but also mediates the adhesion of endothelial cell and matrix by sensing the surrounding environment, leading to further tumor invasion and metastasis (6). It has been observed that VCAM1 expression is induced in the vascular endothelium of oral squamous cell carcinoma (21). In addition, the abnormal expression of VCAM1 is associated with the metastasis of gastric carcinoma $(11,12)$. In addition, the current study indicated that VCAM1-targeted RNAi is able to effectively inhibit the gene and protein expression of VCAM1 as well as the proliferation of oral squamous carcinoma cells, which may provide an experimental basis for the diagnosis and treatment of colorectal cancer.

Nevertheless, the occurrence and development of oral squamous cell carcinoma is associated with the aberrant expression of multiple genes, as well as a variety of in vitro and in vivo factors (3). Previous studies have indicated that succinobucol-loaded nanoparticles exhibit therapeutic efficacy in the metastasis of breast cancer to the lung by inhibiting VCAM1 expression (22). Furthermore, anti-VCAM1 treatment is able to significantly decrease cancer-endothelial adhesion and block fusion (21). Until recently, studies on gene therapy of oral squamous carcinoma primarily focused on single-target gene treatments (4). Despite this progress, treatments targeting multiple genes have not been investigated in vitro and in vivo. The results of the present study potentially provide a theoretical basis for future animal studies and multi-gene targeting therapies in oral squamous carcinoma.

In conclusion, VCAM1-targeted RNAi effectively inhibits the gene and protein expression of VCAM1, as well as the proliferation of oral squamous carcinoma cells. These results may provide an experimental reference for the diagnosis and treatment of colorectal cancer. 


\section{Acknowledgements}

The present study was supported by the Shandong Natural Science Foundation of China (grant no. ZR2013HL008) and the Science and Technology Project of Shandong Education Department (grant no. J12LK08).

\section{References}

1. Chen YJ, Lin SC, Kao T, Chang CS, Hong PS, Shieh TM and Chang KW: Genome-wide profiling of oral squamous cell carcinoma. J Pathol 204: 326-332, 2004.

2. Woolgar JA, Rogers S, West CR, Errington RD, Brown JS and Vaughan ED: Survival and patterns of recurrence in 200 oral cancer patients treated by radical surgery and neck dissection. Oral Oncol 35: 257-265, 1999.

3. Aktas E, Uzman M, Yildirim O, Sahin B, Buyukcam F, Aktas B, Yilmaz B, Yildirim AM, Basyigit S, Yeniova O, et al: Assessment of hepatic steatosis on contrast enhanced computed tomography in patients with colorectal cancer. Int J Clin Exp Med 7: 4342-4346, 2014.

4. Wen F, He S, Sun C, Li T and Wu S: PIK3CA and PIK3CB expression and relationship with multidrug resistance in colorectal carcinoma. Int J Clin Exp Pathol 7: 8295-8303, 2014.

5. Siegel R, Ward E, Brawley O and Jemal A: Cancer statistics, 2011: The impact of eliminating socioeconomic and racial disparities on premature cancer deaths. CA Cancer J Clin 61: 212-236, 2011.

6. Francavilla C, Maddaluno L and Cavallaro U: The functional role of cell adhesion molecules in tumor angiogenesis. Semin Cancer Biol 19: 298-309, 2009.

7. Garton KJ, Gough PJ, Philalay J, Wille PT, Blobel CP, Whitehead RH, Dempsey PJ and Raines EW: Stimulated shedding of vascular cell adhesion molecule 1 (VCAM-1) is mediated by tumor necrosis factor-alpha-converting enzyme (ADAM 17). J Biol Chem 278: 37459-37464, 2003.

8. Rose DM, Cardarelli PM, Cobb RR and Ginsberg MH: Soluble VCAM-1 binding to alpha4 integrins is cell-type specific and activation dependent and is disrupted during apoptosis in T cells Blood 95: 602-609, 2000

9. Wu TC: The role of vascular cell adhesion molecule-1 in tumor immune evasion. Cancer Res 67: 6003-6006, 2007.

10. Chen Q and Massagué J: Molecular pathways: VCAM1 as a potential therapeutic target in metastasis. Clin Cancer Res 18: 5520-5525, 2012.

11. Semba S, Kodama Y, Ohnuma K, Mizuuchi E, Masuda R, Yashiro M, Hirakawa K and Yokozaki H: Direct cancer-stromal interaction increases fibroblast proliferation and enhances invasive properties of scirrhous-type gastric carcinoma cells. Br J Cancer 101: 1365-1373, 2009.
12. Ding YB, Chen GY, Xia JG, Zang XW, Yang HY and Yang L: Association of VCAM-1 overexpression with oncogenesis, tumor angiogenesis and metastasis of gastric carcinoma. World J Gastroenterol 9: 1409-1414, 2003.

13. Zhao XP, Wang M, Song Y, Song K, Yan TL, Wang L, Liu K and Shang ZJ: Membrane microvesicles as mediators for melanoma-fibroblasts communication: Roles of the VCAM-1/VLA-4 axis and the ERK1/2 signal pathway. Cancer Lett 360: 125-133, 2015.

14. Kokovay E, Wang Y, Kusek G, Wurster R, Lederman P, Lowry N, Shen Q and Temple $\mathrm{S}$ : VCAM1 is essential to maintain the structure of the SVZ niche and acts as an environmental sensor to regulate SVZ lineage progression. Cell Stem Cell 11: 220-230, 2012.

15. Yan J, Jiang Y, Ye M, Liu W and Feng L: The clinical value of lymphatic vessel density, intercellular adhesion molecule 1 and vascular cell adhesion molecule 1 expression in patients with oral tongue squamous cell carcinoma. J Cancer Res Ther 10 (Suppl): C125-C130, 2014.

16. Hannon GJ: RNA interference. Nature 418: 244-251, 2002.

17. Warnock JN, Merten OW and Al-Rubeai M: Cell culture processes for the production of viral vectors for gene therapy purposes. Cytotechnology 50: 141-162, 2006.

18. Aoki T, Shimizu S, Urano E, Futahashi Y, Hamatake M, Tamamura H, Terashima K, Murakami T, Yamamoto N and Komano J: Improvement of lentiviral vector-mediated gene transduction by genetic engineering of the structural protein Pr55 Gag. Gene Ther 17: 1124-1133, 2010.

19. Sun LG, Song YF, Liu L, Yang YC, Wang F and Wang LF: Correlations between the expression of vascular cell adhesion molecule-1 gene and clinical pathological characteristics and angiogenesis in oral squamous cell carcinoma. Shanghai Kou Qiang Yi Xue 17: 569-573, 2008 (In Chinese).

20. Livak KJ and Schmittgen TD: Analysis of relative gene expression data using real-time quantitative PCR and the 2(-Delta Delta C(T)) method. Methods 25: 402-408, 2001.

21. Lee N, Shin S, Chung HJ, Kim DK, Lim JM, Park H and Oh HJ: Improved quantification of protein in vaccines containing aluminum hydroxide by simple modification of the Lowry method. Vaccine 33: 5031-5034, 2015.

22. Song K, Zhu F, Zhang HZ and Shang ZJ: Tumor necrosis factor- $\alpha$ enhanced fusions between oral squamous cell carcinoma cells and endothelial cells via VCAM-1/VLA-4 pathway. Exp Cell Res 318: 1707-1715, 2012.

(i) $\odot$ This work is licensed under a Creative Commons Attribution-NonCommercial-NoDerivatives 4.0 International (CC BY-NC-ND 4.0) License. 